\title{
A THREE-YEAR STUDY OF THE GDPR AND THE CONSUMER
}

\author{
Wanda Presthus and Hanne Sørum \\ Kristiania University College, Prinsens gate 7-9, 0107 Oslo, Norway
}

\begin{abstract}
This paper presents an empirical study of the General Data Protection Regulation (GDPR) from the consumer perspective. Based on data collected through an online survey questionnaire over a period of three years (2018-2020), we identify trends and patterns among Norwegian consumers. The findings show that the GDPR has not significantly affected consumer awareness, nor level of control over their own personal data. Concerning the enhanced rights of deletion, data portability and access to personal data, the patterns are similar, revealing that most of our respondents 'might execute' their rights. Pertaining to website cookies, most of the respondents are unsure, and the general trend from 2019 to 2020 reveals a greater uncertainty. This paper contributes with new insights for the industry and to the information privacy research field.
\end{abstract}

\section{KEYWORDS}

Information Privacy, the General Data Protection Regulation (GDPR), Consumer Rights, Empirical Study

\section{INTRODUCTION}

The General Data Protection Regulation (GDPR) was introduced in 2018. There were many thoughts and opinions about the regulation regarding consequences for private persons and companies (Jarbekk \& Sommerfeldt, 2019; Presthus, Sørum, \& Andersen, 2018). The GDPR replaces about 40 privacy laws from European countries with one unified regulation (The European Parliament and the Council, 2016). The GDPR affects any company that handles personal data and has customers belonging to the EU or EEA. Existing research has revealed that consumers do not care too much about their privacy, especially when the benefits surpass the challenges, for example when shopping online (Krasnova \& Veltri, 2010). However, privacy has interested researchers since the invention of the hand-held camera in the 1900-century (Solove, 2020), but people reacts differently regarding their privacy (Westin, 2003). In the wake of the GDPR, this paper is guided by the following research questions: (1) to what extent has the GDPR affected consumer awareness of privacy rights and (2) to what extent do consumers make use of their enhanced rights? Herein, the focus is on before and after the introduction of the regulation.

\section{RELATED RESEARCH OF PRIVACY AND SECURITY}

Research on information privacy enjoys substantial attention from researchers. Privacy as a concept is blurred (Solove, 2005) and has sparked interest for more than 100 years among almost all types of researchers (Westin, 2003, Dinev, Xu, Smith, \& Hart, 2013; Lowry, Dinev, \& Willison, 2017). In 1890, Warren and Brandeis defined privacy as the 'right to be left alone' (Bélanger \& Crossler, 2011). This was before the information age, but information privacy became subsumed under the umbrella of privacy sometime after (Smith, Dinev, $\& \mathrm{Xu}, 2011)$. Due to its long and inter-disciplinary existence, several studies have aimed to define information privacy. Definitions tend to take either an individual or an organisational perspective. An example of an individual perspective includes 'one's ability to manage information about oneself' (Bélanger, Hiller, \& Smith, 2002). From the organisational perspective, we find 'a set of problems arising from the ways organizations process personal information' (Solove, 2005). Despite the many definitions, a reoccurring theme is control over personal information (Popovič, Smith, Thong, \& Wattal, 2018). Control, however, has been debated. 
It has been argued that an individual's perception of control does not lead to information privacy: 'Conversely, the individual may not perceive (s)he has control, yet the environmental and interpersonal elements may create perceptions of general privacy' (Laufner and Wolfe, 1977, cited in Smith et al., 2011, p. 995). Thus, control is only a mediating variable in the general privacy system. According to Smith et al. (2011), there is also a debate on the distinction between security and privacy. Along with anonymity and secrecy, this has added to the confusion about information privacy (Dinev et al., 2013). Culnan and Williams claim that security is one aspect of privacy: 'Security is about protecting personal information, while privacy is broader and encompasses permission and use of personal information. Privacy is difficult to achieve without security' (Culnan \& Williams, 2009 p. 674). However, in this study, information privacy and security are viewed as interdependent. When it comes to the evolution of research, papers have been typically conceptual, falling into three categories: literature reviews, forward-looking research agendas and measurement instruments for other empirical researchers. Another theme is antecedents of information privacy, such as the perception of individuals with trust as a major issue. A third theme has focused on consequences, such as the reduced effectiveness of direct marketing and resistance to new technologies. The fourth theme is protecting the individual (Popovič et al., 2018). Finally, research has evolved from motivation for studying information privacy, via guidelines for companies and consequences, to privacy-protecting algorithms and privacy in healthcare and social networks.

\subsection{Violations, Consequences, Concerns, and Attitudes}

A breach or violation of information privacy can entail many consequences, both for the individual and for the organisation. It is not only the organisation who is the 'bad wolf'; hackers are examples of individuals that can harm organisations. According to (Chatterjee, Sarker, \& Valacich, 2015), hacking, phishing and spoofing have become a major security concerns for society, individuals and organisations. Other risks from a pure networking site perspective, such as cyber-attack risks and privacy abuse risks, have been identified (Dinev et al., 2006). The same applied to e-business consumers who were concerned with the misuse of personal information, monitoring, spam, hackers and viruses and risk with payment (Kaapu \& Tiainen, 2009). Security in usage of computer systems is a vital component for many stakeholders (Novakovic, McGill, \& Dixon, 2009). From an individual perspective, examples include harmful consequences like surveillance, identification, blackmail, and decisional interference (Solove, 2005).

The advances in technology do not only entail harmful activities. Martin presents beneficial and questionable uses of big data (Martin, 2015), such as treating cancer (beneficial) versus discrimination in insurance (questionable). However, there is yet another actor at play: algorithms. If an algorithm makes questionable decisions, who is to blame? An attempt to solve this issue, known as algorithmic transparency, has emerged from artificial intelligence and machine learning (Watson \& Nations, 2019). Watson and Nations also study the balance of beneficial and questionable uses by introducing a 'creepiness scale' that goes from 'this is helpful' on the one end to 'this is so wrong' on the other. Examples of 'this is helpful' include movie suggestions on Netflix. 'This is so wrong' include targeted ads from personal injury lawyers after visiting an emergency room at a hospital and health insurance decisions based on your friends on Facebook. However, Watson and Nations express the need for more research on creepiness as a construct.

\subsection{Conceptual Frameworks}

Several conceptual frameworks have been developed and tested over the years. Numerous studies have drawn on the privacy calculus and the privacy paradox. The privacy calculus model deals with how the individual makes an informed decision of trading personal data for benefits, such as discounted merchandise or maintaining friends on social media (Presthus \& Vatne, 2019). In other words, the benefits will surpass the risk of losing one's privacy (Krasnova \& Veltri, 2010). However, the privacy paradox model suggests that individuals tend to make decisions that contradict their dispositional privacy concerns (Alashoor, 2019). Thus, the privacy calculus model aims to predict an individual's decision, while the privacy paradox phenomenon reflects a weak relationship (or a mismatch) between dispositional privacy concerns and disclosure behaviours. The debate surrounding these frameworks is ongoing; for example, some argue that the privacy calculus is obsolete (Knijnenburg et al., 2017). 
Mason's privacy, accuracy, property and accessibility (PAPA) framework is seminal in Information Systems (Mason, 1986). Even though the PAPA framework was created in 1986, it is still highly relevant according to (Peslak, 2006; Parrish, 2010; Presthus \& Andersen, 2017). Law professor Solove's taxonomy of privacy has four categories: information collection, information processing, information dissemination and invasion. Building on Solove (2005), Culnan and Williams (2009) identify two main potential problems in data breach: information reuse and unauthorised access. Bélanger and Crossler's framework conjoins individual, group, organisation and societal information, and illustrates various privacy concern constructs (Bélanger \& Crossler, 2011); however, it does not include illegal parties. The extended privacy model (Conger, Pratt, \& Loch, 2013) includes illegal parties in addition to individuals/consumers, vendors/providers, data sharing partners and illegal entities. The model illustrates how advanced technologies can evade individuals/consumers and make it possible for illegal entities to collect data. Thus, the privacy calculus or privacy paradox become obsolete. Some of the aforementioned frameworks also comprise government involvement and legal regulations.

\subsection{The General Data Protection Regulation (GDPR)}

The GDPR was implemented in 2018, replacing about 40 privacy laws from European countries with one unified regulation (The European Parliament and the Council, 2016). The GDPR consists of 99 Articles, and it can be found here: https://gdpr-info.eu/. As observed in the information privacy literature, there are several stakeholders related to the GDPR. Colesky, Hoepman, \& Hillen (2016) present an overview with three actors and eight strategies for organisations to comply with the GDPR. As reported by Lomas (2016), the opportunities were fewer than the challenges for companies, but one benefit typically dealt with cleaning up data. Other potential benefits are that GDPR compliance can lead to satisfied customers and competitive advantages (Lomas, 2016). An empirical study conducted by Kleindienst et al. (2017) revealed that customers will value companies that offer insights before the customers have asked for them. Somewhat contradictory to other studies, the empirical paper by Crossler and Posey warns companies against using individual privacy concerns as promotion, though it might be tempting. Developers and marketers should rather focus on the company's ability, benevolence and integrity. These three factors constitute a company's trustworthiness (Crossler \& Posey, 2017). The GDPR Article 17: The right to erasure, also known as 'The right to be forgotten', has gained interest. For example, Mantelero points out that it is not anything new and can be traced back to Warren and Brandeis in 1890 (Mantelero, 2013), while others discuss practical difficulties in removing data posted on the Internet (Koops, 2011; Korenhof et al., 2015). In addition, the GDPR does not give individuals the right to be completely forgotten. They can only claim this right if consent has not been given or if data are being used for other purposes than first stipulated (Lee \& Pickering, 2016). An empirical study amongst 62 companies found that Article 17 was considered the most challenging (Presthus et al., 2018). Despite being a European regulation, researchers outside the EU have started to incorporate the GDPR in their research, with Watson and Nations (2019) as one example.

Summing up the related work, one conclusion is that information privacy and the GDPR are about protecting the individual from potential harmful activities. Another conclusion is that if one should attempt to conjoin all the models and concepts into one illustration, it would likely be enormous and difficult to grasp, however there are some common denominators amongst the models.

\section{METHOD}

Collecting primary data is encouraged within privacy and security research (Lowry et al., 2017). This article is based on an empirical, online survey questionnaire that has been distributed three times. In addition to related research, the survey is grounded in the legal document regulation (EU) 2016/679 of the European Parliament and of the council of 27 April 2016, which can be downloaded as a PDF from here: https://gdpr-info.eu/. The document lists 173 recitals and 99 Articles. A person, individual, consumer, citizen or alike is referred to as a 'data subject' in the regulation. The survey started with three questions concerning the data subject's perceived awareness about privacy, control over personal data and knowledge about the GDPR. These are some of the reasons why the GDPR was implemented and are based on the recitals. Second, four selected rights were 
investigated: right to erasure (Article 17), data portability (Article 20), right of access (Article 15) and cookies/consent (Recitals 30/32 and Articles 6 and 7).

The empirical study was carried out over a period of three years (2018-2020). We visited the classrooms during lectures and the students completed the survey while we were present. This way, we could address any practical issues that arose (but there were none). The questionnaire included Likert-scale, multiple choice and open-ended questions (requesting qualitative answers). The software tool SurveyMonkey® was used for conducting the survey, and the data were collected through a web-link created by the software. The same survey was replicated for all three years, except from a few changes that were needed concerning the questions, as the first survey was distributed before implementation of the GDPR, while the two last surveys was distributed after. It should also be noted that the survey in 2018 had fewer open comment fields compared to 2019 and 2020. After completing the first survey in 2018, the respondents commented that they wanted more opportunities to write text in addition to the predefined answer alternatives. As a result of this, additional open comments fields were included in the questionnaire in 2019 and 2020. Moreover, not everyone who started the survey completed it. The average time to complete the survey was five minutes (reported by the survey tool). After the surveys were completed, the data were visualised by using Microsoft Excel $®$. The aim was to generate overall trends and patterns.

The survey was replicated three times, with some minor adjustments due to the time the surveys were conducted (pre- and post-implementation of the GDPR). Pilot testing of the questionnaires was carried out before launching the survey and adjusted according to the feedback from the respondents. The aim was to ensure that the respondents understood the meaning of the questions and the use of answer alternatives.

\section{FINDINGS AND DISCUSSION}

The number of respondents in 2018 was 220, in 2019 it was 327 and in 2020 it reached 444. In 2018 and 2019, the typical respondent was male between 18-25 years old. Meanwhile, in 2020, the typical respondent was female but still in the same age group. Consequently, younger students in higher education in Norway dominated. While it must be acknowledged that it was not the same respondents that participated in all three surveys, they are still from the same target group (namely younger people).

As described above, the first investigation was the data subjects' own perceptions of the general awareness of privacy, whether they think they have control over their personal data and knowledge about the GDPR. The results are virtually identical for all three years. There is a clear peak of respondents who state that they have medium awareness, followed by a high degree. Regarding to what extent the respondents experience control over personal data: the majority state that they have partial control, followed by having no control at all.

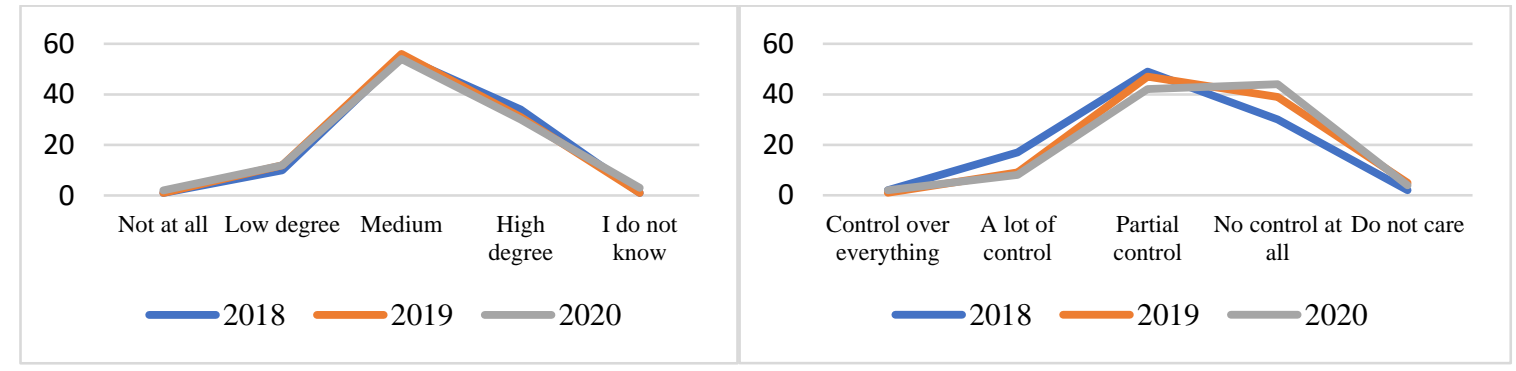

Figures 1 and 2. Percentage of general awareness of privacy and perceived control among the respondents

The graphs in Figures 1 and 2 has a similar pattern for all three years. Does this mean that the effect of the GDPR has not been as desired, at least not in the short term? The respondents experienced less control in 2020 compared to 2018. One possible explanation could be that today, people have more knowledge about all the data that is out there versus what they were aware of in 2018. Regarding knowledge of the GDPR, the findings show that the variations are greater among the three years. Consequently, the respondents demonstrate a greater disparity than is the case of the two other background questions. Moreover, the respondents had the greatest knowledge of the GDPR in 2019 and the lowest in 2020. This can have many explanations. In 2020, this hype of the GDPR may have decreased, and less attention is given by newspapers, TV and web news. 


\subsection{Enhanced Rights}

As illustrated in Figure 3, more respondents stated in 2018 that they would 'definitely' make use of these rights (green columns), while fewer had actually executed them in 2019 and in 2020 (amber columns). Furthermore, there has been a small decline in the number who have used the new rights when comparing the numbers between 2019 and 2020. One reason can be that our respondents are different during the three years.

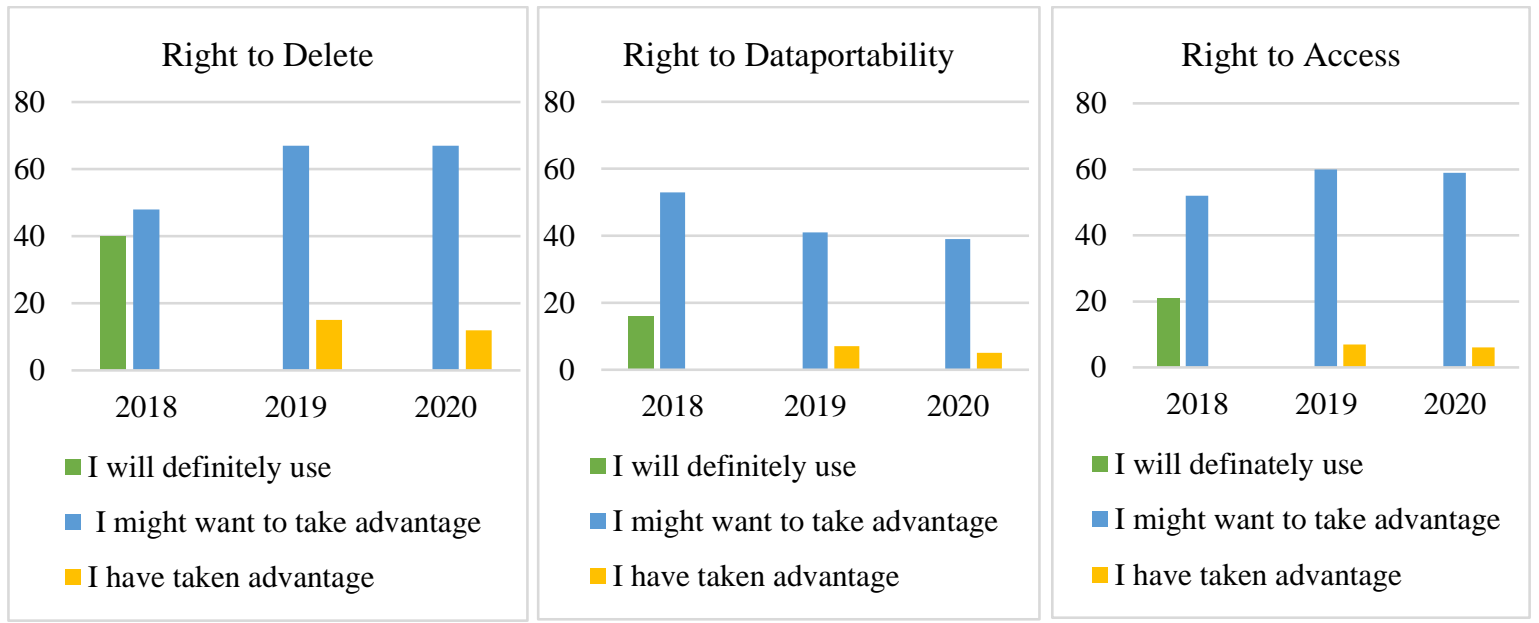

Figure 3. Percentage of the respondents' perception of the deletion of data; data portability and access

Regarding Article 17 about deletion, some comments from the respondents in 2019 read: 'Unless this is serious, I will not take advantage of this. May be good if suspected of illegal activity', while another wrote: 'Feeling poorly informed about how to get personal data deleted'. One example of a comment from the survey conducted in 2020 is: 'Doesn't seem like it works particularly well anyway since they are just retrieving the same information again'. This is a testament to the fact that not all consumers trust that information is indeed deleted. Article 20: Right to Data Portability, allows the data subject to get selected data that the company has acquired about him or her in a machine-readable format (Jarbekk \& Sommerfeldt, 2019). For example, Facebook and Google have created an automated service (Sørum \& Presthus, 2020). The trend and interest have declined somewhat over the years. Compared to 2018, where over $15 \%$ said that this is something they would 'definitely' use, the data reveal that in 2019 and 2020, relatively few have used the right to data portability. Some comments pertaining to this topic from the respondents in 2019 were: 'Downloaded all the data Facebook has about me over time. Quite interesting '; 'Very good that you do not have to lock yourself in to a bad service'; and 'If needed, I will probably use it'. However, not all respondents clearly see the same value in this, as explained in the following: 'Not sure in what context it might be useful'.

The right of access by the data subject, Article 15, is highly comprehensive. It states that the data subjects can request both access to data about him/her, but also information about the purpose, how long it is stored, if it is shared, how to correct or delete and more (Jarbekk \& Sommerfeldt, 2019). Our results are similar. The majority respond that this is something of which they might want to take advantage. Some of the open comments concerning this from 2019 are as follows: 'Scary to read everything Facebook has stored about you. Even things I've deleted.' and 'It is a very good thing that companies must send it in a readable format, because then there is a greater chance that people will bother to read what they answer. If they send you 10 pages of lawyer response, there are many including myself who do not bother to engage me further because it requires too much energy'.

A cookie is a text file that is downloaded on the data subject's computer or mobile device (Presthus \& Andersen, 2017). The GDPR only mentions cookies once (in recital 30); however, it can be argued that the cookie-issue is truly about consent. Recital 32 states: 'Consent should be given by a clear affirmative act establishing a freely given, specific, informed and unambiguous indication of the data subject's agreement to the processing of personal data (...) This could include checking a box when visiting an internet website, (...) Silence, pre-checked boxes or inactivity should not therefore constitute consent'. Article 7: Conditions for consent informs that the data subject has the possibility to consent to the processing of personal data. In 
addition, withdrawal must be easy. However, research has found that $90 \%$ of websites are not allowing users the proper opt-out services regarding cookies and consent (Dabrowski et al., 2019; Sanchez-Rola et al., 2019).

Regarding the questions about website cookies, the respondents are unsure, and the general perception from 2019 to 2020 is a greater uncertainty. A summary of the findings from 2018 is as following: Almost $40 \%$ do not believe that every company will follow the new rules and almost $30 \%$ are unsure how the rule will work in practice. Moreover, $6 \%$ answered that they do not care and $1 \%$ did not know what cookies are. Comparing these findings to the results from 2019 and 2020, we do not see large differences in the respondents' perceptions of cookies. Some of the respondents provided open-ended comments: 'Seems to be nice, but it's hard to pay attention to everything in a day-to-day life that consists of a lot of information. That's why I press ok most of the time', and another one reads: 'Better, but many do not offer the option of refusing, without that box taking over the entire screen'.

Based on three years of studying the GDPR, this paper offers accumulated insights (presented in Table 1).

Table 1. Accumulated insights about the consumer's perspectives on privacy

\begin{tabular}{|c|c|c|}
\hline Insight topic & Consumer's perspective & Typical comments from the survey \\
\hline $\begin{array}{l}\text { General awareness of } \\
\text { privacy }\end{array}$ & Medium degree & \multirow{2}{*}{$\begin{array}{l}\text { The consumers value their personal data, but } \\
\text { acknowledge that they lack knowledge and } \\
\text { control }\end{array}$} \\
\hline Control over personal data & Partial control & \\
\hline Knowledge of the GDPR & $\begin{array}{l}\text { Have heard of, but do not } \\
\text { know what it means }\end{array}$ & $\begin{array}{l}\text { The consumers have heard about the regulation, } \\
\text { but express uncertainty of the content }\end{array}$ \\
\hline Right to be forgotten & \multirow{3}{*}{ Might execute } & \multirow{3}{*}{$\begin{array}{l}\text { The consumers are in favor of the regulation, } \\
\text { but express concerns about the enforcement }\end{array}$} \\
\hline Right to data portability & & \\
\hline Right to access & & \\
\hline
\end{tabular}

Based on the findings, the general pattern is dominated by "medium", "partial" and "might". Why the lack of concern and action from individuals? Based on related research, there are three possible answers. First: The concept is blurred (Solove, 2005), and we do not understand the technology at work behind the scenes of our computers (Presthus \& Andersen, 2017), nor do we understand the 99 paragraphs of the GDPR (Jarbekk \& Sommerfeldt, 2019). Many websites that consumers visit collect large amounts of data about individuals, our usage patterns and how we behave in a digital world. In many ways, it can be positive, but on the other hand, it is useful to know the questionable uses as well. Existing research has revealed that some companies fail at announcing this, for example on their websites. At the same time, it can be challenging to familiarize yourself with the regulations, considering legal rights and what they mean for the individual. Second: We make (more or less) calculated decisions about trading our information for benefits (Dinev et al., 2006), however, we are probably selling ourselves short, or there is a lack of business models that offer monetary payment rather than paying with personal data (Presthus \& Vatne, 2019; Solove, 2020). Consequently, as consumers, we should become more aware of what our personal data is used for in a business purpose context and the high price consumers may end up paying by not being more conscious. Third: Some individuals have resigned (Few, 2018; Solove, 2020), as have companies in a supply chain, thinking 'everyone does it, why should not we' (Martin, 2015). Martin further describes negative externality, meaning that the big data industry is causing indirect harm to individuals. However, only the companies will profit from the passive attitudes of consumers.

\section{LIMITATIONS AND FURTHER RESEARCH}

No research is without limitations. Regarding method, Lowry et al. advise against using student sampling or sampling from one organization when it comes to privacy research (Lowry et al., 2017). This paper is guilty of both; however, the chosen organization is large, and the student body consists of a wide range of disciplines. Other limitations related to method are the focus on younger people, and their opinions do not necessarily reflect those of the rest of the population. Future research can compare younger people and seniors. Moreover, this study is relatively descriptive, but the aim was to paint an overall picture, as there is a lack of empirical research. Another limitation is the use of survey questions. Further research could therefore include qualitative interviews. International studies are also encouraged. For example, the California Consumer Privacy Act 
(CCPA) went into effect on January $1^{\text {st }}, 2020$ in the US (Watson \& Nations, 2019). It should be interesting to observe the influence of the CCPA in the future and how it relates to the GDPR. As demonstrated in the Related Research section, the conceptual models for information privacy are numerous, and we are therefore somewhat reluctant to add yet another at this point.

\section{CONCLUSION}

This study has investigated to what extent the GDPR affects consumer awareness of privacy rights and whether consumers make use of their enhanced rights. The data from a survey replicated three times indicate that the GDPR has not affected the consumer. The respondents state virtually the same level of awareness and control over personal data over the three years. Regarding knowledge about the GDPR, the pattern shows that it declined in 2020 compared to the level of knowledge in the two previous years. Concerning deletion, data portability and access to personal data, the patterns are similar and reveal that most of the respondents 'might execute' their enhanced rights. Pertaining to website cookies, most respondents are unsure, and the general perception from 2019 to 2020 reveals a greater uncertainty. This study contributes with practical insights based on empirical data to industry and to the information privacy research field.

\section{REFERENCES}

Alashoor, T. (2019). Explaining the Privacy Paradox through Identifying Boundary Conditions of the Relationship between Privacy Concerns and Disclosure Behaviors. Doctor of Philosophy Dissertation, Georgia State University.

Bélanger, F., \& Crossler, R. E. (2011). Privacy in the Digital Age: A Review of Information Privacy Research in Information Systems. MIS Quarterly, 35(4), pp. 1017-1041.

Bélanger, F., Hiller, J. S., \& Smith, W. J. (2002). Trustworthiness in electronic commerce: the role of privacy, security, and site attributes. The journal of strategic Information Systems, 11(3-4), 245-270.

Chatterjee, S., Sarker, S., \& Valacich, J. S. (2015). The behavioral roots of information systems security: Exploring key factors related to unethical IT use. Journal of Management Information Systems, 31(4), 49-87.

Colesky, M., Hoepman, J.-H., \& Hillen, C. (2016). A critical analysis of privacy design strategies. Paper presented at the Security and Privacy Workshops (SPW), 2016 IEEE.

Conger, S., Pratt, J. H., \& Loch, K. D. (2013). Personal information privacy and emerging technologies. Information Systems Journal, 23, pp.401-417.

Crossler, R. E., \& Posey, C. (2017). Robbing Peter to pay Paul: Surrendering privacy for security's sake in an identity ecosystem. Journal of the Association for Information Systems, 18(7), pp. 487-515.

Culnan, M. J., \& Williams, C. C. (2009). How ethics can enhance organizational privacy: lessons from the choicepoint and TJX data breaches. MIS Quarterly, pp. 673-687.

Dabrowski, A., Merzdovnik, G., Ullrich, J., Sendera, G., \& Weippl, E. (2019). Measuring cookies and web privacy in a post-gdpr world. Paper presented at the International Conference on Passive and Active Network Measurement.

Dinev, T., Belletto, M., Hart, P., Russo, V., Serra, I., \& Colautti, C. (2006). Privacy calculus model in e-commerce - a study of Italy and the Unites States. European Journal of Information Systems, 4(15), pp. 389-402.

Dinev, T., Xu, H., Smith, J. H., \& Hart, P. (2013). Information privacy and correlates: an empirical attempt to bridge and distinguish privacy-related concepts. European Journal of Information Systems, 22(3), pp. 295-316.

Few, S. (2018). Big Data, Big Dupe. A little book about a big bunch of nonsense: Analytic Press.

Jarbekk, E., \& Sommerfeldt, S. (2019). Personvern og GDPR i praksis: Cappelen Damm, ISBN 9788202604066.

Kaapu, T., \& Tiainen, T. (2009). Consumers' Views on Privacy in E-Commerce. Scandinavian Journal of Information Systems, 21(1), pp. 3-22.

Knijnenburg, B., Raybourn, E., Cherry, D., Wilkinson, D., Sivakumar, S., \& Sloan, H. (2017). Death to the Privacy Calculus? Available at SSRN 2923806

Koops, B.-J. (2011). Forgetting footprints, shunning shadows: A critical analysis of the right to be forgotten in big data practice. SCRIPTed, 8, 229.

Korenhof, P., Ausloos, J., Szekely, I., Ambrose, M., Sartor, G., \& Leenes, R. (2015). Timing the right to be forgotten: A study into "time" as a factor in deciding about retention or erasure of data Reforming European data protection law (pp. 171-201): Springer. 
Krasnova, H., \& Veltri, N. (2010). Privacy Calculus on Social Networking Sites: Explorative Evidence from Germany and USA". Paper presented at the 43rd Hawaii International Conference on System Sciences, Honolulu, HI, USA. January 5-8.

Lee, P., \& Pickering, K. (2016). The general data protection regulation: A myth-buster. Journal of Data Protection \& Privacy, 1(1), pp. 1-5.

Lomas, E. (2016). Data Protection and GDPR Opportunites and Challenges. IRMS London Particpatory workshop hosted by UCL, 7 July 2016., pp. 1-6.

Lowry, P. B., Dinev, T., \& Willison, R. (2017). Why security and privacy research lies at the centre of the information systems (IS) artefact: proposing a bold research agenda. European Journal of Information Systems, 26, pp. 546-563.

Mantelero, A. (2013). The EU Proposal for a General Data Protection Regulation and the roots of the 'right to be forgotten'. Computer Law \& Security Review, 29(3), pp. 229-235.

Martin, K. E. (2015). Ethical issues in the big data industry. MIS Quarterly Executive, 14(2), pp. 67-85.

Mason, R. O. (1986). Four ethical issues of the information age. MIS Quarterly, 10(1), pp. 5-12.

Novakovic, L., McGill, T., \& Dixon, M. (2009). Understanding User Behavior towards Passwords through Acceptance and Use Modelling. International Journal of Information Security and Privacy, 3(1), pp. 11-29.

Parrish, J. L. (2010). PAPA knows best: Principles for the ethical sharing of information on social networking sites. Ethics and Information Technology, 12(2), pp. 187-193.

Peslak, A. R. (2006). PAPA revisited: A current empirical study of the Mason framework. Journal of Computer Information Systems, 46(3), pp. 117-123.

Popovič, A., Smith, H. J., Thong, J. Y. L., \& Wattal, S. (2018). Information Privacy. MIS Quarterly Research Curations, Ashley Bush and Arun Rai, Eds., http://misq.org/research-curations,.

Presthus, W., \& Andersen, L. R. (2017). Information Privacy from a Retail Management Perspective. Paper presented at the In Proceedings of the 25th European Conference on Information Systems (ECIS), Guimarães, Portugal, June 5-10, 2017.

Presthus, W., Sørum, H., \& Andersen, L. R. (2018). GDPR compliance in Norwegian Companies. Norsk konferanse for organisasjoners bruk av IT (NOKOBIT). Svalbard 18-20 September 2018.

Presthus, W., \& Vatne, D. M. (2019). A Survey on Facebook Users and Information Privacy. Procedia Computer Science, 164, pp. 39-47.

Sanchez-Rola, I., Dell'Amico, M., Kotzias, P., Balzarotti, D., Bilge, L., Vervier, P.-A., \& Santos, I. (2019). Can I Opt Out Yet? GDPR and the Global Illusion of Cookie Control. Paper presented at the Proceedings of the 2019 ACM Asia Conference on Computer and Communications Security.

Smith, H. J., Dinev, T., \& Xu, H. (2011). Information Privacy Research: An Interdisciplinary Review. MIS Quarterly, 35(4), pp. 989-1015.

Solove, D. J. (2005). A taxonomy of privacy. U. Pa. L. Rev., 154, pp. 477-560.

Solove, D.J. (2020) Privacy + Security Blog. News, Developments, and Insights. https://teachprivacy.com/cartoon-thehistory-of-privacy/ Visited November 11, 2020.

Sørum, H., \& Presthus, W. (2020). Dude, Where's My Data? The GDPR in Practice, from a Consumer's Point of View. Information Technology \& People, pp.1-18.

The European Parliament and the Council. (2016). REGULATION (EU) 2016/679 OF THE EUROPEAN PARLIAMENT AND OF THE COUNCIL of 27 April 2016. Official Journal of the European Union, available through https://gdpr-info.eu/, pp. 1-88.

Watson, H. J., \& Nations, C. (2019). Addressing the Growing Need for Algorithmic Transparency. Communications of The Association for Information Systems, 45(1), 26, pp. 488-510.

Westin, A.F. (2003) Social and Political Dimensions of Privacy. Journal of Social Issues, 59(2), pp. 431-453. 